\title{
Flow cytometric analysis of Clostridium difficile adherence to human intestinal epithelial cells
}

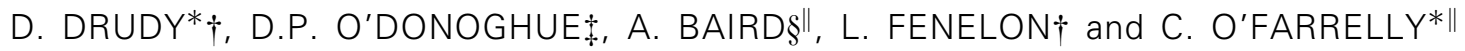 \\ * Education and Research Centre, †Department of Microbiology, †Department of Gastroenterology, St \\ Vincent's University Hospital, Dublin 4, §Department of Pharmacology, "Conway Institute of Molecular and \\ Biomedical and Research, University College Dublin, Ireland
}

\begin{abstract}
Clostridium difficile is the most common cause of diarrhoea in hospitalised patients. Bacterial adherence to gut epithelial cells is a likely prerequisite to infection and toxin production. A novel flow cytometric method was developed for detecting adherence of $C$. difficile to human colonic and small intestinal epithelial cells (EC) and human intestinal cell lines. Small intestinal and colonic EC were isolated from biopsy specimens with mucolytic and chelating agents. Adherence of fluorochrome-labelled $C$. difficile to EC was measured by flow cytometry and was calculated as increase in median fluorescent intensity $(\Delta M F I)$. Cells with bacteria attached could be distinguished easily from cells alone or cells with unlabelled bacteria attached. Toxin-positive $C$. difficile adhered to colonic and small intestinal EC ( $\triangle$ MFI mean 21.2 SD 16.7, $\mathrm{n}=33$ and 16.5 SD 20.7, $\mathrm{n}=19$ respectively). The toxin-negative strain also adhered to both epithelial cell types ( $\triangle$ MFI 26.1 SD 32.5, $\mathrm{n}=17$ and 18.3 SD 31.3, $\mathrm{n}=16$ ). Adherence of toxin-positive $C$. difficile to the intestinal cell lines Caco-2 ( $\triangle$ MFI 9.4 SD 4.4, $n=14$ ) and HT29 ( $\Delta$ MFI 8.1 SD 3.1, $n=12$ ) was quantifiable, although at a significantly lower level than with primary colonic epithelial cells. Adherence of the toxin-negative strain was slightly lower, $\triangle M F I$ 6.5 SD 1.8, $\mathrm{n}=9$ with Caco-2 cells and $\triangle$ MFI 6.0 SD 2.0, $\mathrm{n}=10$ with HT29 cells. Adherence of $\boldsymbol{C}$. difficile to epithelial cell lines was blocked with $C$. difficile antiserum, confirming specificity of adherence. In conclusion, flow cytometry is a useful approach to quantifying adherence of $\boldsymbol{C}$. difficile to human colonic and small intestinal epithelial cells. Binding of toxin-negative as well as toxin-positive bacteria was detectable by this approach. Analysis of $C$. difficile adherence to target cells may have important implications for the understanding of the pathogenesis of $C$. difficile-related disease.
\end{abstract}

\section{Introduction}

Clostridium difficile, a gram-positive spore-forming anaerobic bacillus, is the most common cause of infectious diarrhoea in hospitalised patients [1]. Optimal conditions for colonisation and infection develop when antibiotic treatment leads to disruption of the normal colonic flora $[2,3]$. Infection results in a wide spectrum of disease ranging from mild selflimiting diarrhoea to severe colitis and pseudomembranous colitis, which can often be fatal [4]. The sporeforming ability of this organism makes it difficult to eradicate from the hospital environment - thus hindering infection control measures, allowing cross-

Date received 26 July 2000; revised version accepted 26 Oct. 2000.

Corresponding author: Dr C. O'Farrelly (e-mail: cliona. ofarrelly@ucd.ie). infection, and resulting in increased morbidity and mortality [5-7].

Adherence of bacteria to intestinal epithelium is known to be a prerequisite for colonisation and infection of the gastrointestinal tract by many gastrointestinal pathogens [8-10]. The intestinal epithelium is the primary site of contact for pathogens with host cells and plays an important role in the cross-talk between epithelial cells, luminal micro-organisms and immune cells. The role played by pathogens that adhere to epithelial cells and invade the underlying mucosa has been well documented [11-18]. Furthermore, nuclear factor kappa $\mathrm{B}(\mathrm{NF}-\kappa \mathrm{B})$, the transcription factor that regulates the expression of many pro-inflammatory cytokines, inflammatory enzymes and adhesion molecules, is activated following bacterial adherence, suggesting a common pathway for activation of several mechanisms [19-24]. 
C. difficile has been shown to associate with colonic mucus from hamsters [25]. Previous reports have demonstrated adherence to human intestinal cell lines by light microscopy [26,27], although the levels of adherence observed were low $(<1$ bacterium/cell at $37^{\circ} \mathrm{C}$ ). Adherence levels increased following bacterial heat-shock treatment but the relevance of bacterial heat shock to in-vivo infection is unclear. Adherence of $C$. difficile to non-intestinal epithelial cell lines has also been demonstrated [27]. Again low levels of adherence were observed at $37^{\circ} \mathrm{C}$, with increased adherence seen after bacterial heat shock. Waligora et al. studied environmental factors that might influence $C$. difficile adherence [28]. Acidic pH, decreased iron availability and high calcium and sodium concentrations all increased $C$. difficile adherence to Vero cells. Furthermore, these authors found no significant difference in adherence of toxigenic and non-toxigenic $C$. difficile strains. However, for most of these studies, nonintestinal epithelial cell lines were used, rather than intestinal epithelial cells which may be more relevant physiologically.

The ability of $C$. difficile to attach to human primary colonic and small bowel epithelial cells has not been examined, despite the fact that adherence of this organism is likely to be the primary step in pathogenesis, preceding toxin release. This is mainly due to the difficulties associated with the long-term culture of primary human epithelial cells. The present study examined adherence of a toxin-positive and a toxinnegative strain of $C$. difficile to human intestinal cells. A method for removal of viable intestinal epithelial cells from colonic and small bowel epithelium was devised in a previous study [29]. Cells prepared by this methodology were used to develop a flow cytometric method for assessing adherence of fluorescently labelled bacteria to human intestinal epithelial cells.

\section{Materials and methods}

\section{Bacterial strains}

A toxin-producing $C$. difficile strain (ATCC 9689) was obtained from Oxoid (Basingstoke, Hampshire). A toxin-negative strain (R10567) was obtained from the Public Health Laboratory Service Anaerobe Reference Unit (Cardiff, Wales). Both strains were tested with the C. difficile Tox AB test (Tech lab, Blacksburg, VA, USA) to determine toxin production. Bacteria were cultured anaerobically on Columbia Blood Agar (Oxoid) plates for $36 \mathrm{~h}$ at $37^{\circ} \mathrm{C}$, and the strains were stored on bacterial preserver beads at $-70^{\circ} \mathrm{C}$ (Technical Services Consultants, Lancashire). For each assay, bacteria were grown on blood agar and then transferred into Fastidious Anaerobe Broth (LabM, Bury, homes) and incubated anaerobically for $36 \mathrm{~h}$. Cultures were harvested by centrifugation at $1500 \mathrm{~g}$ for $10 \mathrm{~min}$ and resuspended in phosphate-buffered saline (PBS, $\mathrm{pH}$ 6.8; Oxoid). Bacteria in suspension were quantified by optical density reading at $490 \mathrm{~nm}$, comparison with McFarland standards and viable plate counts. Appropriate dilutions of bacterial suspensions were spread on Columbia blood agar plates and incubated anaerobically at $37^{\circ} \mathrm{C}$ for $48 \mathrm{~h}$.

\section{Preparation of fluorochrome}

The fluorochrome BCECF/AM 2', 7'-bis-(Carboxyethyl)-5(6')-carboxyfluorescein acetomethyl esther (Calbiochem-Novabiochem, Nottingham) was used in this study. It diffuses into viable cells and is cleaved by cytosolic esterases to yield intracellularly trapped indicator BCECF. A $1 \mathrm{mM}$ stock solution of BCECF/AM was prepared in acetone. This was sterile-filtered, dispensed into small volumes and stored at $-20^{\circ} \mathrm{C}$.

\section{Fluorochrome labelling of bacteria}

Bacteria were labelled with fluorochrome by incubating $1 \times 10^{9}$ bacteria $/ \mathrm{ml}$ with $1 \mathrm{mM} \mathrm{BCECF} / \mathrm{AM}$ in acetone at $37^{\circ} \mathrm{C}$ to give a working solution of $1 \mu \mathrm{M}$ BCECF/AM. Time course experiments in which bacteria were incubated with fluorochrome for 20, 40 and $60 \mathrm{~min}$, respectively, revealed optimal labelling at $60 \mathrm{~min}$. Excess fluorochrome was removed by washing in PBS five times at $1500 \mathrm{~g}$. Fluorescent label uptake was assessed by microscopy and flow cytometry.

\section{Isolation of human intestinal epithelial cells}

Ethical approval for this study was obtained from the Hospital Ethics and Research Committee at St Vincent's University Hospital (Dublin, Ireland) and patient consent was obtained on every occasion. Biopsy tissue was taken from patients undergoing routine endoscopy/colonoscopy for various bowel diseases. Two biopsies were fixed for routine histological examination to exclude abnormal pathology. Results were only taken from adhesion experiments with biopsies from patients in whom pathology was excluded. The remaining (four) colonic or small bowel biopsies were placed immediately in Hanks's Balanced Salts Solution (HBSS; Gibco, Paisley) pH 6.8 with fetal calf serum (FCS; Gibco) $5 \%$ and transported directly to the laboratory. The biopsies were then placed in a $1 \mathrm{mM}$ solution of ethyl diamine tetra-acetic acid (EDTA; BDH)/di-tri-threitol (DTT; Sigma) in HBSS without calcium or magnesium at $37^{\circ} \mathrm{C}$, placed on a rotator and allowed to rotate freely for $60 \mathrm{~min}$. The supernate was removed with a sterile pasteur pipette and cells were pelleted by centrifugation, washed once in Roswell Park Memorial Institute (RPMI; Gibco) medium. The cells were counted with a haemocytometer and viability was assessed with an ethidium bromide/acridine orange stain (EB/AO; Sigma). Cells were diluted in a known volume of $\mathrm{EB} / \mathrm{AO}$ and when viewed under UV light, viable cells were identified by green fluorescence whereas dead cells emitted orange 
fluorescence [30]. Cells were adjusted to a $1 \times 10^{6} / \mathrm{ml}$ suspension and stored on ice until used.

\section{Cell culture}

Caco-2 cells (a human ileocaecal epithelial cell line) were obtained from the European Collection of Cell Culture (ECACC). Cells were grown in Dulbecco's medium (Gibco) containing glucose supplemented with fetal calf serum $5 \%$, amphotericin B, penicillin/streptomycin, HEPES buffer and non-essential amino acids (NEAA) (all from Gibco), in polystyrene tissue-culture flasks until confluent. HT29 cells (a human colonic epithelial cell line) were obtained from the American Tissue Culture Collection (ATCC). Cells were grown in modified McCoys medium (Gibco), supplemented with fetal calf serum 5\%, amphotericin B, penicillin/streptomycin and HEPES buffer in polystyrene tissueculture flasks until confluent. Before adherence assays, both cell lines were incubated with antibiotic-free medium for $24 \mathrm{~h}$. Cells were removed from tissueculture flasks with an EDTA-trypsin suspension, counted in a haemocytometer and adjusted to the relevant concentration.

\section{Adherence assay}

Fluorescently labelled bacteria $\left(1 \times 10^{8}\right)$ were incubated with $1 \times 10^{5}$ epithelial cells for $30 \mathrm{~min}$ at $37^{\circ} \mathrm{C}$ in PBS. Negative controls included epithelial cells in PBS (Sigma) and epithelial cells incubated with nonfluorescently labelled bacteria. After incubation, cells were washed three times in PBS to remove nonadherent bacteria. Cells were then fixed with paraformaldehyde (PFA; Sigma) 1\%, before examination by flow cytometry.

\section{Flow cytometry}

Human intestinal epithelial cells with adherent $C$. difficile were measured in a FACScan flow cytometer (Becton Dickinson, Oxford). With use of a dot plot display of forward scatter (FSC) versus side scatter (SSC), the machine was gated to include epithelial cells and to exclude cellular debris, intra-epithelial lymphocytes and non-adherent bacteria. Cells inside the gated area were stained with FITC-labelled Ber Ep 4 antibody (DAKO, Glostrup, Norway) to confirm their epithelial origin. A total of 10000 events was acquired and the data were analysed with the Cell Quest software program from Becton Dickinson. This program produces histograms of each individual particle sample and calculates the mean and median fluorescence intensity for each cell population. Median fluorescent intensity (MFI) values were compared for test populations and negative controls. Cells with fluorescently labelled bacteria attached show a shift in fluorescence as a result of bacterial binding when compared with the autofluorescence expressed by epithelial cells alone.

\section{Semi-quantification of bacterial adherence}

The approximate number of bacteria adhering to each epithelial cell was determined as follows. Colony counts were performed on the bacterial suspensions added to the epithelial cells and bacterial suspensions removed from the epithelial cells at the end of the adherence assay (the pooled washings obtained from the washing steps). Serial dilutions of bacteria were spread on Columbia agar plates, which were incubated anaerobically for $48 \mathrm{~h}$. Colony-forming units (cfu) were then counted for both bacterial suspensions. The number of epithelial cells per sample was determined by the Cell Quest program on the flow cytometer with a specific anti-epithelial antibody. The total number of adherent bacteria was determined by subtracting the bacteria removed from those initially added. The total number of adherent bacteria was divided by the known number of epithelial cells. This allowed calculation of the number of adherent bacteria per epithelial cell.

\section{Preparation of $C$. difficile antiserum and determination of specificity of adherence}

C. difficile grown on Columbia blood agar was heattreated by autoclaving at $121^{\circ} \mathrm{C}$ for $20 \mathrm{~min}$. Rabbits were inoculated subcutaneously with $1 \times 10^{9}$ bacteria/ $\mathrm{ml}$ emulsified in Freund's complete adjuvant and given two subsequent injections of bacteria with Freund's incomplete adjuvant 2 weeks apart. The rabbits were bled 1 week after the last immunisation. The presence of $C$. difficile antibodies in serum was confirmed by ELISA. To determine the specificity of the interaction between bacteria and epithelial cells, bacteria were preincubated with diluted anti- $C$. difficile antibodies for $60 \mathrm{~min}$ before the adherence assay.

\section{Statistical analysis}

All data were analysed with Statview (1989) and Microsoft Excel packages. Students $t$ test was used to compare differences in the adherence of toxin-producing and non-producing $C$. difficile strains to various cell types.

\section{Results}

\section{BCECF labelling of $C$. difficile}

Optimal uptake of label was achieved at $60 \mathrm{~min}$ (data not shown). The MFI was calculated for unlabelled and fluorescently labelled bacteria as mean 3.32 SD 1.55 and 26.44 SD 3.47; $\mathrm{n}=>200$ (Fig. 1), respectively.

\section{Isolation of epithelial cells from human intestinal biopsies}

Epithelial cells were identified on the basis of cell size and morphology. Cell viability was examined by $\mathrm{EB} / \mathrm{AO}$ staining and UV microscopy and was $>80 \%$ 

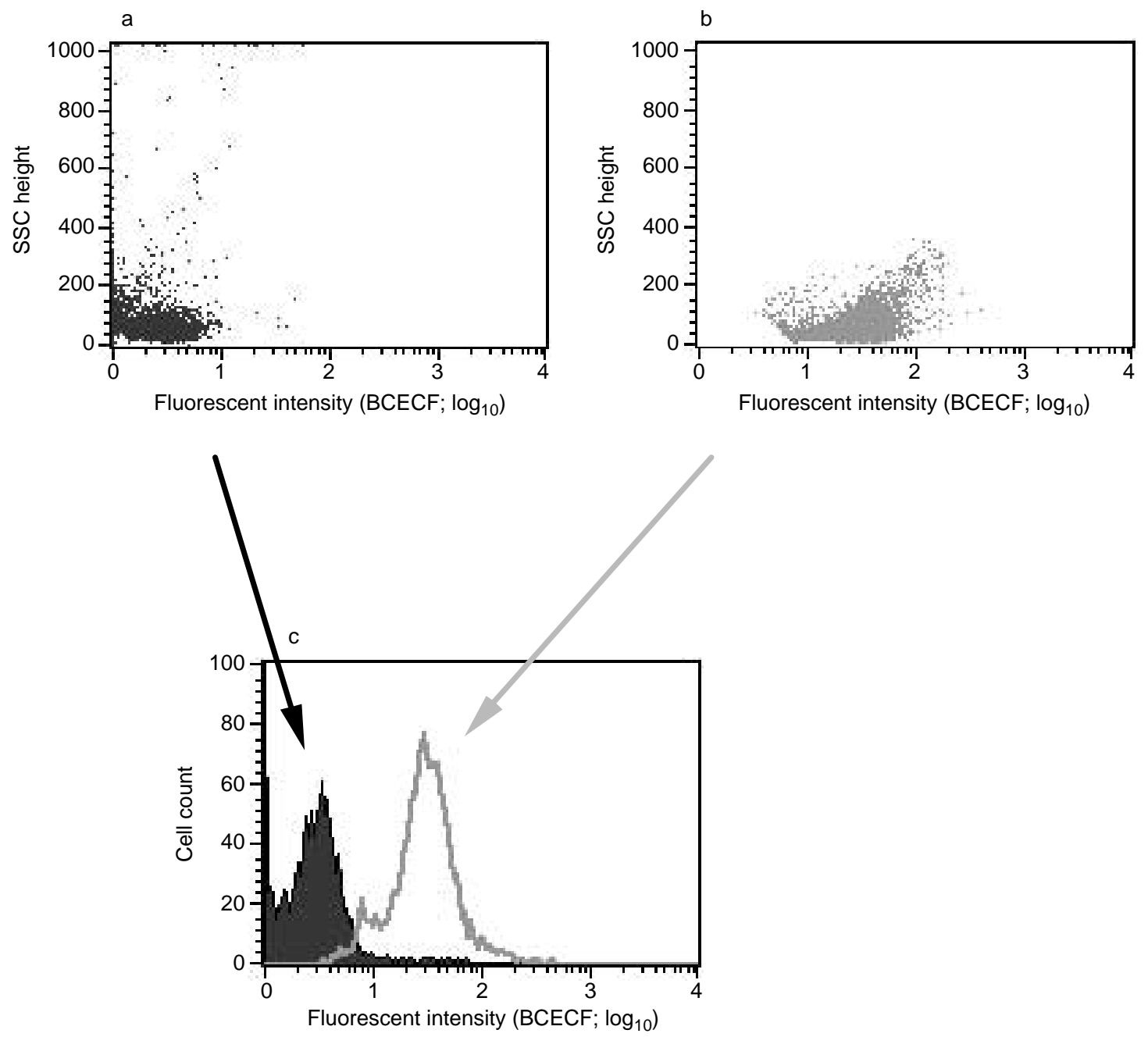

Fig. 1. Fluorochrome uptake by bacterial populations. Dot plot profiles of (a) unlabelled and (b) fluorescently labelled C. difficile. The histogram plot (c) shows the shift in fluorescence seen with the labelled bacteria (open peak) versus the unlabelled bacteria (shaded peak).

and $>90 \%$ for colonic and small intestinal epithelial cells, respectively. Colonic epithelial cell yield varied from 0.8 to $1.9 \times 10^{6}$ from four biopsies (mean $=1.4$ ); small intestinal epithelial cell yield varied from 0.6 to $3.85 \times 10^{6}$ from four biopsies $($ mean $=1.6$ ).

\section{Adherence to primary colonic and small intestinal epithelial cells}

Primary colonic epithelial cells incubated with fluorescently labelled $C$. difficile could be distinguished easily from cells with non-labelled bacteria attached and cells alone (Fig. 2). The adherence was confirmed by light and UV microscopy. The toxigenic strain of $C$. difficile was found to adhere to human colonocytes (Fig. 3a). The difference between fluorescently labelled $C$. difficile binding to primary cells and cells which had been exposed to non-fluorescently labelled bacteria was statistically significant $(\mathrm{p}<0.0001)$. The ability of toxigenic $C$. difficile to adhere to primary small intestinal epithelial cells was also assessed (Fig. 3b) and significant adherence was observed $(\mathrm{p}<0.005)$.
The adherence of the toxin-positive strain to primary colonic epithelial cells was not significantly different from adherence to primary small intestinal epithelial cells. Small intestinal tissue from 20 patients and colonic tissue from 30 patients was studied. The degree of variation in adherence to both types of primary intestinal epithelial cells was considerable.

\section{Adherence to human intestinal epithelial cell lines Caco-2 and HT29}

A toxin-producing $C$. difficile strain was assessed for its ability to adhere to the human intestinal epithelial cell lines, Caco-2 (ileocaecal) and HT29 (colonic) (Fig. 4). Adherence was statistically significant when compared with the negative controls $(\mathrm{p}<0.0001$ for Caco2 cells and $p<0.0001$ for HT29 cells). There was no significant difference in adherence to Caco-2 cells when compared to HT29 cells. Adherence of either $C$. difficile strains to these cell lines, while significantly lower than adherence to primary human colonic epithelial cells, was consistent. 


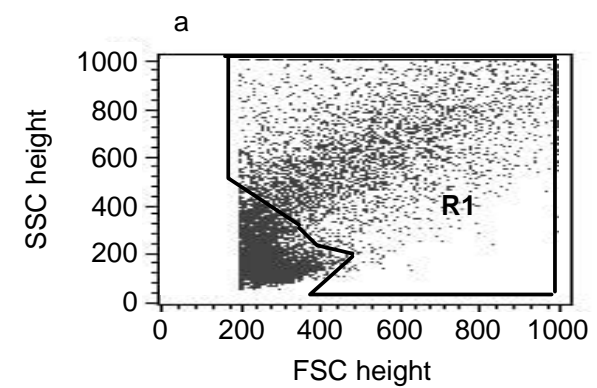

C

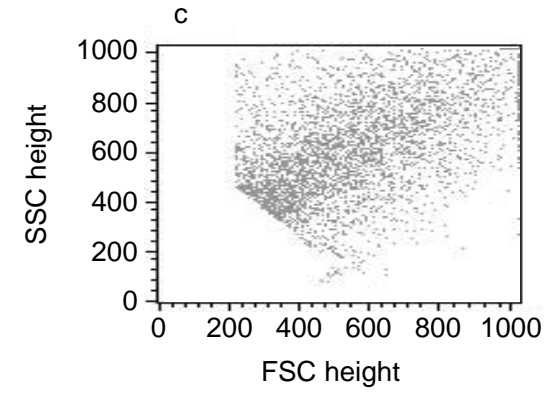

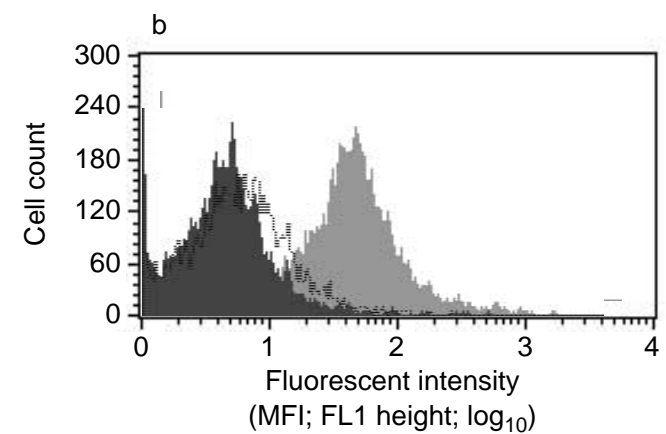

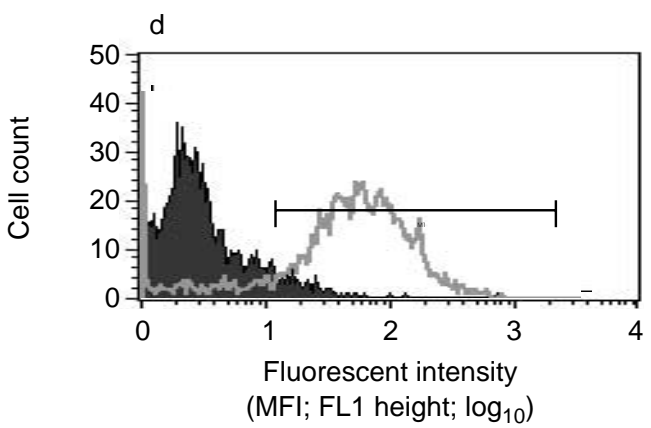

Fig. 2. Flow cytometric analysis of $C$. difficile adherence to human colonic epithelial cells and confirmation of epithelial cell status. (a) Dot plot profile of size versus granularity - forward scatter (FSC) versus side scatter (SSC) analysis of cell populations. The gate drawn (R1) allows analysis of the epithelial cells while eliminating cellular debris, intra-epithelial lymphocytes and non-adherent bacteria. (b) Analysis of $C$. difficile adherence to human primary colonic epithelial cells. The first peak (dark grey) represents cells that have not been exposed to $C$. difficile. The second peak (open) represents cells that have been exposed to unlabelled $C$. difficile. The relative fluorescence expressed by these two populations is similar. The third peak (light grey) represents cells that have been exposed to fluorescently labelled $C$. difficile. The shift in cell population to the right along the fluorescence axis represents bacteria bound to epithelial cells. A median fluorescent intensity (MFI) value can be calculated for each peak. Adherence is expressed as change in MFI ( $\triangle \mathrm{MFI}$, the difference in MFI values between the test and control populations). (c) Dot plot profile of gated (R1) epithelial cell population (FSC versus SSC). (d) Confirmation of epithelial origin using Ber Ep 4. The gated region (R1) in $\mathrm{C}$ demonstrates that $>85 \%$ of the cells stained positive (open peak). The shaded peak shows cells stained with an IgG1 FITC-matched control.

\section{Semi-quantification of adherent bacteria}

Colony counts were done and the approximate numbers of adherent bacteria were estimated; cfu values for the numbers of adherent bacteria observed by flow cytometry confirmed the degree of variation of adherence to primary intestinal epithelial cells when compared with cell lines.

Adherence to primary epithelial cells showed variation in both MFI values (mean, 58.8 SD 47.8; range, 15.8$103.6 ; \mathrm{n}=4$ ) and the numbers of organisms adhering to 10 epithelial cells (mean, 218 SD 176.6; range 56$400 ; n=4)$. Alternatively, adherence to cell lines was much more consistent whether measured by flow cytometry when MFI values (12.9 SD 3.9; 9.0-18.4; $\mathrm{n}=4$ ) or cfu were used to estimate the numbers of organisms adhering to 10 epithelial cells (28 SD 7.5; $21-38 ; \mathrm{n}=4)$.

\section{Adherence of toxigenic versus non-toxigenic $C$. difficile}

Toxin-producing and non-toxin-producing $C$. difficile adhered to primary human intestinal epithelial cells in a similar fashion. The difference between binding by toxigenic and non-toxigenic organisms was not statistically significant with either colonic $(\mathrm{p}=0.28)$ or small bowel $(\mathrm{p}=0.24)$ epithelial cells (Fig. 3). There was no significant difference between these two strains when comparing adherence to either Caco-2 cells $(\mathrm{p}<0.07)$ or HT29 cells $(\mathrm{p}<0.06)$ (Fig. 4).

\section{Inhibition of adherence}

Pre-incubation of bacteria with anti- $C$. difficile specific antisera partially blocked the adherence of $C$. difficile to HT29 cells (Fig. 5). Labelled bacteria adhering to HT29 cells gave a mean MFI value of 7.61 SD 3.37 $(n=6)$. Adherence decreased significantly to 4.10 SD 1.21 for bacteria that had been pretreated with $C$. difficile antisera $(\mathrm{p}<0.03)$. Bacteria incubated with pre-immune antisera showed no change in adherence (7.80 SD 2.53).

\section{Discussion}

In-vitro adherence of $C$. difficile to primary human colonic and small intestinal epithelial cells has not been 
a

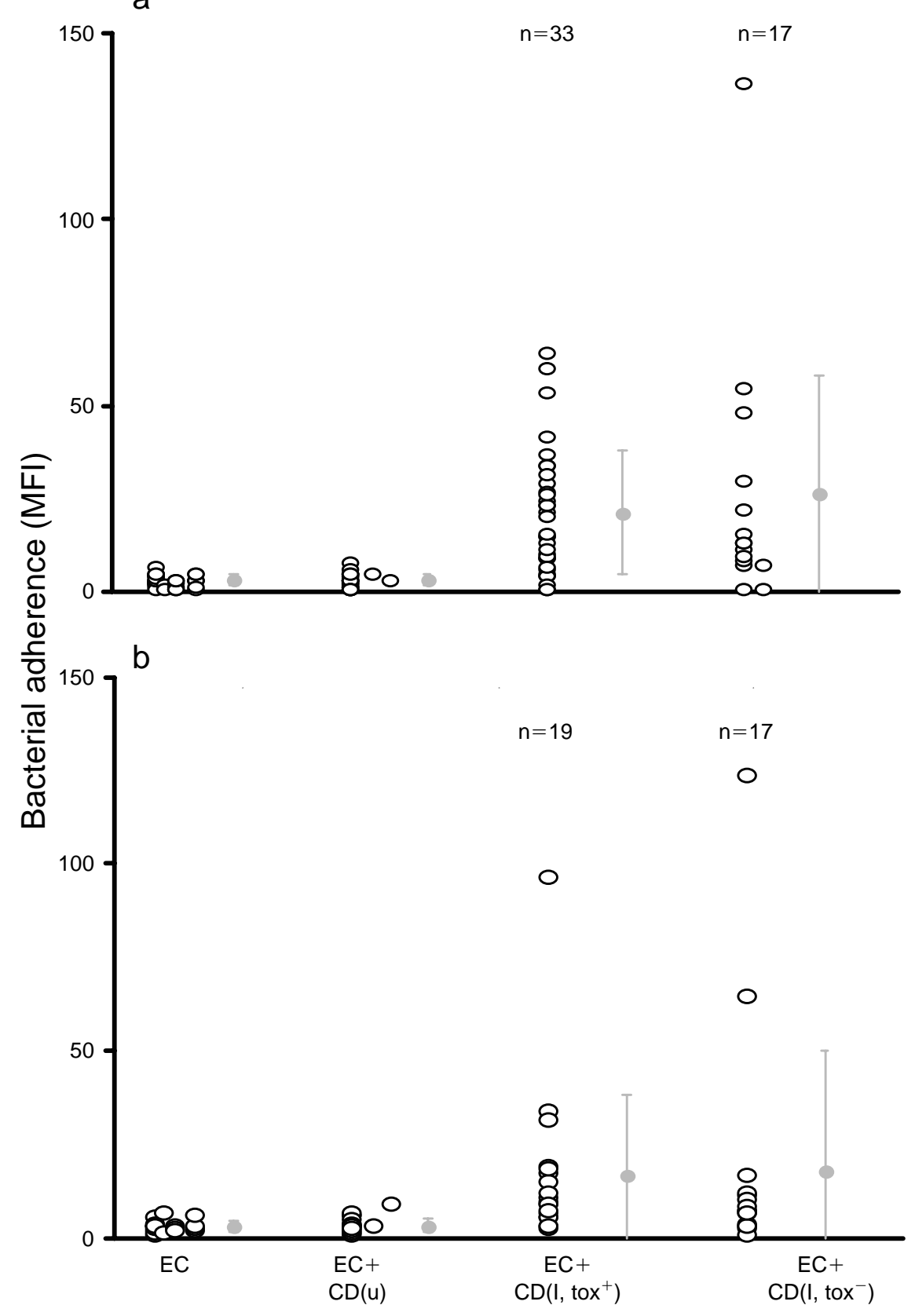

Fig. 3. Adherence of $C$. difficile to human primary colonic and small intestinal epithelial cells. (a) Adherence of $C$. difficile (toxin-positive, $\mathrm{n}=33$; toxin-negative, $\mathrm{n}=17$ ) to cells isolated from colonic biopsy specimens was assessed by flow cytometry. Epithelial cells were gated by size and the results of each separate experiment (o) and the mean value $(\bullet)$ and SD for each group of cells are plotted. Colonic epithelial cells that had not been exposed to bacteria were included for comparison. (b) Adherence of $C$. difficile (toxin-positive, $\mathrm{n}=19$; toxin-negative, $\mathrm{n}=16$ ) to cells isolated from small bowel biopsy specimens was assessed by flow cytometry. Epithelial cells were gated by size and the results of each separate experiment (o) and the mean value $(\bullet)$ and SD for each group of cells are plotted. Small bowel epithelial cells that had not been exposed to bacteria were included for comparison. EC, epithelial cells; CD, C. difficile; (u), unlabelled; $\left(1\right.$, tox $\left.^{+}\right)$, labelled toxin positive; $\left(1\right.$, tox $\left.^{-}\right)$, labelled, toxin negative.

examined previously. Animal models of bacterial adherence have been described but the lack of an invitro model for $C$. difficile infection of the human gut has hindered research in this area. In particular, viable functional epithelial cells from human biopsy specimens have not previously been used for $C$. difficile adherence studies. In this study, flow cytometry has been exploited for the first time to examine $C$. difficile adherence to human intestinal epithelial cells. Large numbers of cells are not required for flow cytometry, so optimal use can be made of the relatively low epithelial cell yields from biopsy specimens. With this approach, it is possible to distinguish differences in cell populations based on changes in fluorescent intensities for test and control 


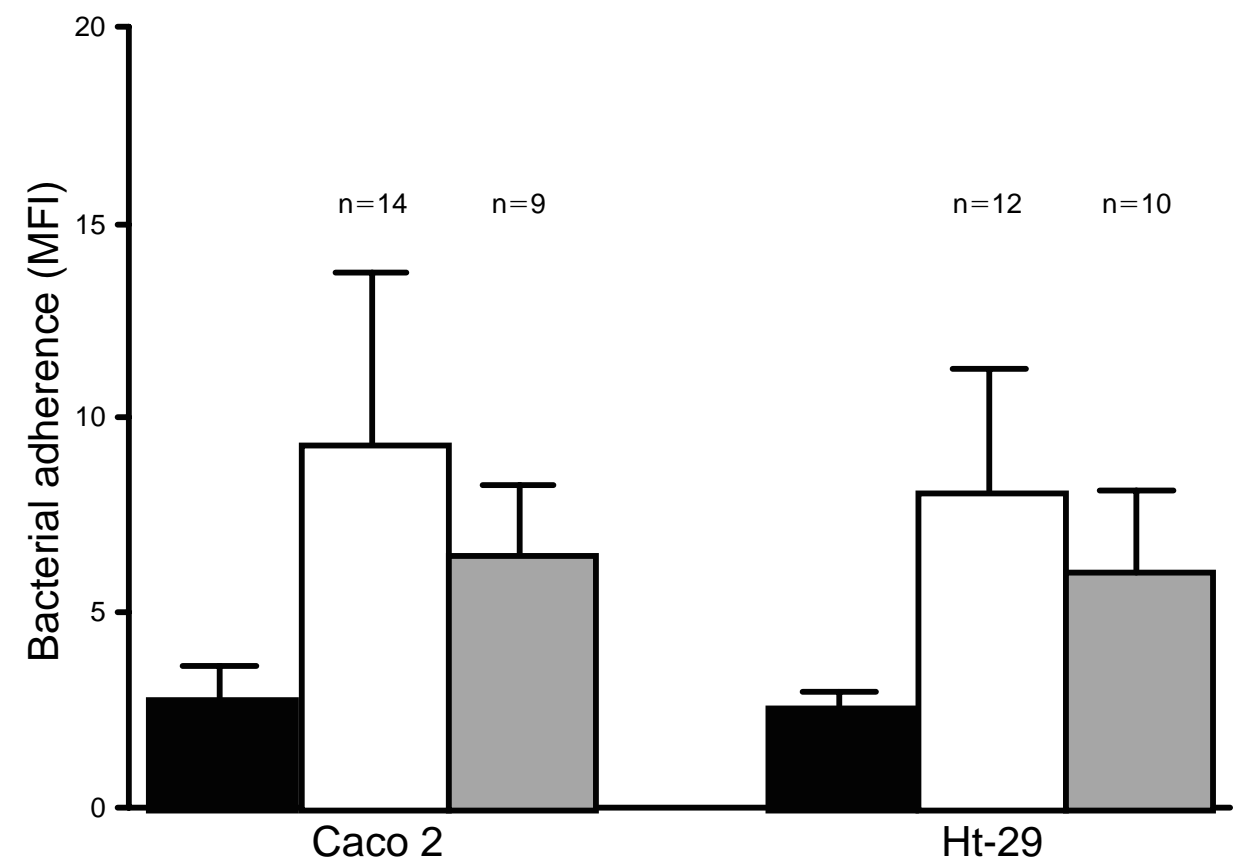

Fig. 4. Adherence of toxin-positive and toxin-negative $C$. difficile to human intestinal cell lines Caco-2 (a) and HT29 (b) assessed by flow cytometry. Mean values and SD are plotted for each group of cells: $\square$, cells that had been exposed to fluorescently labelled toxigenic $C$. difficile; $\square$, cells exposed to non-toxigenic $C$. difficile; $\mathbf{m}$, intestinal epithelial cell populations that had not been exposed to bacteria.

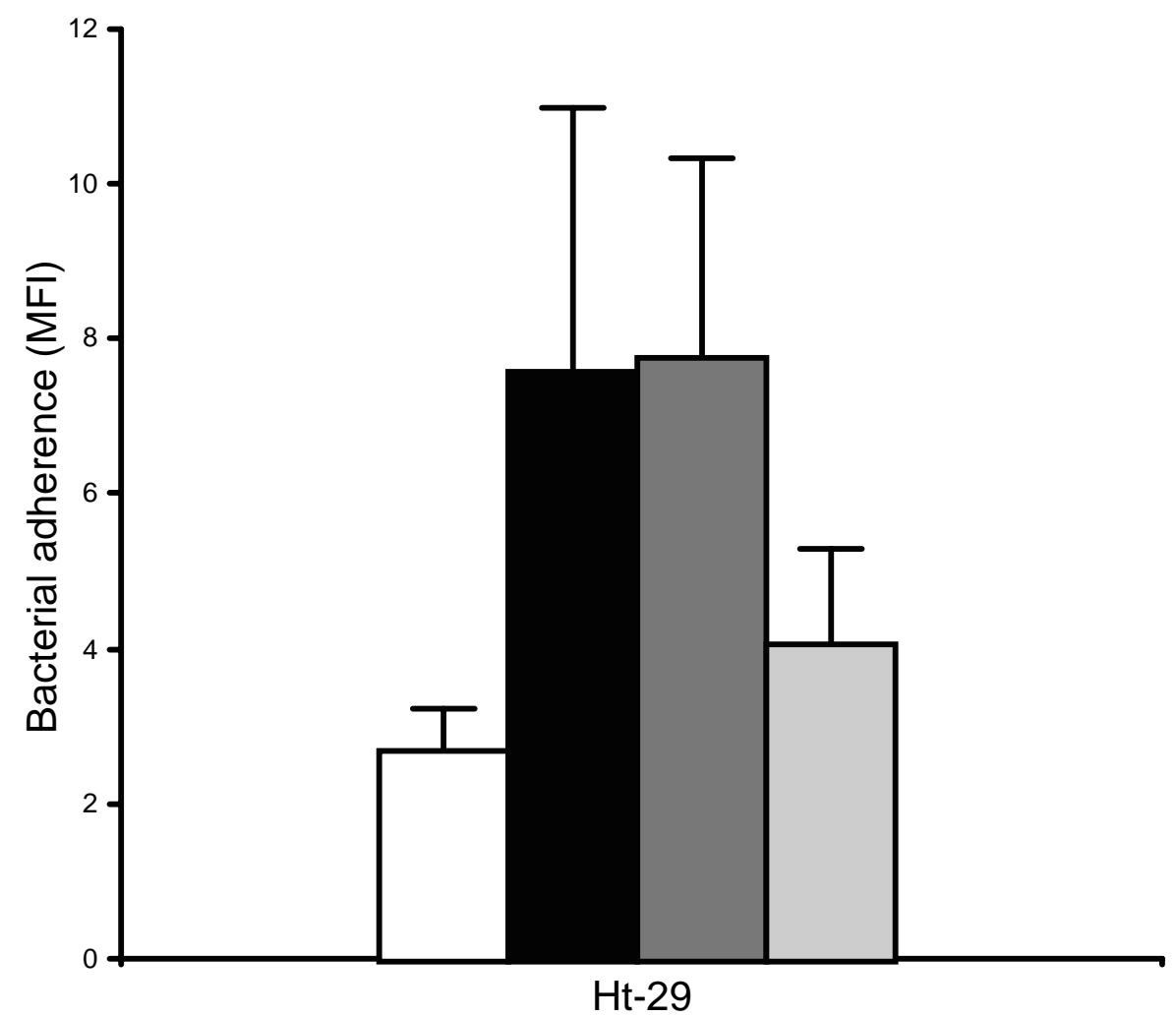

Fig. 5. Inhibition of toxigenic $C$. difficile adherence by polyclonal $C$. difficile antibodies; Median fluorescent intensity of HT29 cells $(\square)$ and HT29 cells with adherent $C$. difficile (ロ). Partial inhibition of $C$. difficile adherence to HT29 cells with $C$. difficile polyclonal antiserum ( $\square$ ) compared with lack of inhibition with pre-immune serum ( $\square$ ). Results represent the mean of three separate experiments and SD.

populations by means of this technical approach. When compared with conventional microscopy, it is also possible to examine much larger numbers of cells in a shorter time period. Moreover, directly labelling the bacteria with a fluorochrome eliminates the need for expensive monoclonal antibodies [31].

Analysis of adherence by light microscopy, electron 
microscopy and radiolabelling has been described previously. Light microscopic methods, while useful, are tedious and time-consuming and may be prone to observer error. Electron microscopy studies require lengthy fixation processes and specific technical expertise. Ideally, the use of radioactive labels should be avoided if possible. Flow cytometry allows analysis of cell populations by virtue of their physical characteristics and has been used previously to assess the adherence of Helicobacter pylori [32]. Initial studies of bacterial adherence by flow cytometry used specific antibodies to the bacterium under investigation. However, direct labelling of the bacteria with a fluorochrome eliminates the need for expensive monoclonal antibodies [31]. Flow cytometry also allows the optimal use of the relatively small numbers of cells isolated from intestinal biopsies and, therefore, may provide a more suitable technical approach to the analysis of bacterial adherence.

C. difficile adherence to intestinal and non-intestinal immortalised epithelial cells has been demonstrated previously [27]. Waligora et al. [28] used a microscopy technique and found that toxigenic and non-toxigenic strains adhered to a kidney epithelial cell line. The present study used flow cytometry to demonstrate adherence of $C$. difficile to two intestinal epithelial cell lines. C. difficile consistently adhered to both Caco-2 and HT29 cell lines. Unlike primary human intestinal epithelial cells, which can survive for only a limited period once they are removed from their natural environment, immortalised cells may be more extensively manipulated in vitro and, therefore, are useful to study. However, many cell lines do not differentiate in culture and may not express all of the functional receptors seen in mature human colonocytes [33]. Thus, while these cell lines are useful for extensive screening studies, primary human enterocytes may have important physiological features, which may explain the significantly higher levels of adherence seen with primary epithelial cells.

In contrast to the consistent patterns of adherence to cell lines, considerable variability in adherence was observed with primary epithelial cells from individual patients. Neither histology reports nor patient charts revealed any apparent explanation for the lack of consistency of adherence to the cells from certain individuals, nor why, in some instances, no adherence at all could be observed. However, in some cases significantly more adherence to the primary cells was seen, with as many as 40 bacteria binding to each cell. The consistent adherence to immortalised cells, albeit at lower levels than that observed with primary cells, suggests genetic or environmental influences on the expression of the intestinal $C$. difficile receptor. Variation in receptor expression and bacterial adherence may also be relevant to the outcome of clinical disease, as not all colonised patients develop $C$. difficile disease $[34,35]$. It is likely that adherence may promote other virulence factors that influence whether patients remain asymptomatically colonised or develop manifestations of disease.

The present study showed that a toxin-positive and a toxin-negative strain of $C$. difficile demonstrated similar adherence to either primary colonic and small intestinal epithelial cells or intestinal epithelial cell lines. Until recently, it was generally accepted that nontoxigenic strains of $C$. difficile that do not possess genes for either toxin are non-pathogenic. However, a number of studies have described symptomatic patients from whom only toxin-negative isolates were cultured. Wren et al. found that 28 of 172 strain types from 62 symptomatic patients did not produce either enterotoxin A or cytotoxin B [36]. McFarland et al. found no significant difference in toxin production between isolates from asymptomatic versus symptomatic patients [37]. In their symptomatic patient group, three of 35 strains were not toxin producers. While it is possible that other virulence factors are involved in the pathogenesis of this disease, the adherence of bacterial strains - whether toxigenic or non-toxigenic - is likely to be a prerequisite to pathology.

In vitro, $C$. difficile binds to small intestinal epithelial cells almost as well as to colonic epithelial cells; however, $C$. difficile infection in vivo is generally restricted to the colon. Isolation of $C$. difficile from the small bowel indicates that this region of the gut may act as a reservoir for $C$. difficile infection, although it is rarely a site of infection. Testore et al. isolated $C$. difficile from jejunal specimens from 3 of 100 patients, none of whom had gastrointestinal symptoms [38]. However, cases of pseudomembranous enteritis with no colonic involvement have been reported [39,40] and we have seen a similar case. Several factors including $\mathrm{pH}$, peristalsis, bile acids and normal flora may influence differences in manifestations of adherence at these intestinal sites, thus explaining the rarity of this pathology in the small bowel in vivo.

The ability of $C$. difficile to adhere to intestinal epithelial cells is likely to be the primary step in pathogenesis and this characteristic is exhibited by both toxigenic and non-toxigenic strains. The ability to produce toxins does not appear to affect adherence, but binding to primary colonic epithelial cells was significantly greater than adherence to either Caco-2 or HT29 cells, or to Vero cells, as shown by others [28]. Adhesion may allow bacteria to target toxins. It is possible that toxins may be involved in the promotion of mucosal association or that toxin-induced cellular damage might expose masked receptor sites. The method described here would be suitable for screening the ability of clinical $C$. difficile strains to adhere to intestinal epithelial cells. The use of primary intestinal epithelial cells and the increased adherence seen with this cell type demonstrates their optimal use as a more physiologically relevant model of gut epithelium than 
immortalised intestinal cells. This assay could also be adapted for screening novel therapeutic agents for their ability to block or interfere with adherence.

We acknowledge the Health Research Board, Ireland for financial support.

\section{References}

1 Kelly CP, LaMont JT. Clostridium difficile infection. Annu Rev Med 1998; 49: 375-90.

2 Borriello SP. 12th C. L. Oakley lecture. Pathogenesis of Clostridium difficile infection of the gut. $J$ Med Microbiol 1990; 33: 207-215.

3 Spencer RC. The role of antimicrobial agents in the aetiology of Clostridium difficile-associated disease. J Antimicrob Chemother 1998; 41 Suppl C: 21-27.

4 Borriello SP, Wilcox MH. Clostridium difficile infections of the gut: the unanswered questions. J Antimicrob Chemother 1998; 41 Suppl C: 67-69.

5 Worsley MA. Infection control and prevention of Clostridium difficile infection. J Antimicrob Chemother 1998; 41 Suppl C: 59-66.

6 Riley TV, Codde JP, Rouse IL. Increased length of hospital stay due to Clostridium difficile associated diarrhoea [letter]. Lancet 1995; 345: 455-456.

7 Frost, F, Craun GF, Calderon RL. Increasing hospitalization and death possibly due to Clostridium difficile diarrheal disease. Emerg Infect Dis 1998; 4: 619-625.

8 Kagnoff MF, Eckmann L. Epithelial cells as sensors for microbial infection. J Clin Invest 1997; 100: 6-10.

9 Raupach B, Mecsas J, Heczko U, Falkow S, Finlay BB. Bacterial epithelial cell cross talk. Curr Top Microbiol Immunol 1999; 236: 137-161.

10 Eckmann L, Kagnoff MF, Fierer J. Intestinal epithelial cells as watchdogs for the natural immune system. Trends Microbiol 1995; 3: $118-120$.

11 Jung HC, Eckmann L, Yang S-K et al. A distinct array of proinflammatory cytokines is expressed in human colon epithelial cells in response to bacterial invasion. $J$ Clin Invest 1995; 95: 55-65.

12 Finlay BB. Interactions of enteric pathogens with human epithelial cells. Bacterial exploitation of host processes. $A d v$ Exp Med Biol 1997; 412: 289-293.

13 Isberg RR. Discrimination between intracellular uptake and surface adhesion of bacterial pathogens. Science 1991; 252: 934-938.

14 Giannasca KT, Giannasca PJ, Neutra MR. Adherence of Salmonella typhimurium to Caco-2 cells: identification of a glycoconjugate receptor. Infect Immun 1996; 64: 135-145.

15 Rigothier MC, Coconnier MH, Servin AL, Gayral P. A new in vitro model of Entamoeba histolytica adhesion, using the human colon carcinoma cell line Caco-2: scanning electron microscopic study. Infect Immun 1991; 59: 4142-4146.

16 Benítez JA, Spelbrink RG, Silva A et al. Adherence of Vibrio cholerae to cultured differentiated human intestinal cells: an in vitro colonization model. Infect Immun 1997; 65: 3474-3477.

17 Mantle M, Husar SD. Adhesion of Yersinia enterocolitica to purified rabbit and human intestinal mucin. Infect Immun 1993; 61: $2340-2346$.

18 Scaletsky ICA, Pedroso MZ, Oliva CA, Carvalho RLB, Morais $\mathrm{MB}$, Fagundes-Neto U. A localized adherence-like pattern as a second pattern of adherence of classic enteropathogenic Escherichia coli to HEp-2 cells that is associated with infantile diarrhea. Infect Immun 1999; 67: 3410-3415.

19 Rasmussen SJ, Eckmann L, Quayle AJ et al. Secretion of proinflammatory cytokines by epithelial cells in response to Chlamydia infection suggests a central role for epithelial cells in chlamydial pathogenesis. J Clin Invest 1997; 99: 77-87.

20 Svanborg C, Hedlund M, Connell $\mathrm{H}$ et al. Bacterial adherence and mucosal cytokine responses. Receptors and transmembrane signaling. Ann N Y Acad Sci 1996; 797: 177-190.
21 Huang GT-J, Eckmann L, Savidge TC, Kagnoff MF. Infection of human intestinal epithelial cells with invasive bacteria upregulates apical intercellular adhesion molecule-1 (ICAM)1) expression and neutrophil adhesion. J Clin Invest 1996; 98: $572-583$.

22 Eckmann L, Stenson WF, Savidge TC et al. Role of intestinal epithelial cells in the host secretory response to infection by invasive bacteria. Bacterial entry induces epithelial prostaglandin $\mathrm{h}$ synthase-2 expression and prostaglandin E2 and F2alpha production. J Clin Invest 1997; 100: 296-309.

23 Elewaut D, DiDonato JA, Kim JM, Truong F, Eckmann L, Kagnoff MF. NF-kappa B is a central regulator of the intestinal epithelial cell innate immune response induced by infection with enteroinvasive bacteria. J Immunol 1999; 163: 1457-1466.

24 Eaves-Pyles, T, Szabó C, Salzman AL. Bacterial invasion is not required for activation of NF-kappaB in enterocytes. Infect Immun 1999; 67: 800-804.

25 Borriello SP, Welch AR, Barclay FE, Davies HA. Mucosal association by Clostridium difficile in the hamster gastrointestinal tract. J Med Microbiol 1988; 25: 191-196.

26 Eveillard, M, Fourel V, Barc M-C et al. Identification and characterization of adhesive factors of Clostridium difficile involved in adhesion to human colonic enterocyte-like Caco-2 and mucus-secreting HT29 cells in culture. Mol Microbiol 1993; 7: 371-381.

27 Karjalainen T, Barc M-C, Collignon A et al. Cloning of a genetic determinant from Clostridium difficile involved in adherence to tissue culture cells and mucus. Infect Immun 1994; 62: 4347-4355.

28 Waligora A-J, Barc M-C, Bourlioux P, Collignon A, Karjalainen T. Clostridium difficile cell attachment is modified by environmental factors. Appl Environ Microbiol 1999; 65: 4234-4238.

29 Madrigal L, Lynch S, Feighery C, Weir D, Kelleher D, O'Farrelly C. Flow cytometric analysis of surface major histocompatibility complex class II expression on human epithelial cells prepared from small intestinal biopsies. J Immunol Methods 1993; 158: 207-214.

30 Lee S-K, Singh J, Taylor RB. Subclasses of $\mathrm{T}$ cells with different sensitivities to cytotoxic antibody in the presence of anesthetics. Eur J Immunol 1975; 5: 259-262.

31 Logan RPH, Robins A, Turner GA, Cockayne A, Borriello SP, Hawkey CJ. A novel flow cytometric assay for quantitating adherence of Helicobacter pylori to gastric epithelial cells. J Immunol Methods 1998; 213: 19-30.

32 Clyne M, Drumm B. Adherence of Helicobacter pylori to the gastric mucosa. Can J Gastroenterol 1997; 11: 43-48.

33 Zweibaum A. [Differentiation of human colon cancer cells: a new approach to cancer of the colon.] Ann Gastroenterol Hepatol (Paris) 1993; 29: 257-261; discussion 261-262.

34 Kyne L, Warny M, Qamar A, Kelly CP. Asymptomatic carriage of Clostridium difficile and serum levels of IgG antibody against toxin A. $N$ Engl J Med 2000; 342: 390-397.

35 Shim JK, Johnson S, Samore MH, Bliss DZ, Gerding DN. Primary symptomless colonisation by Clostridium difficile and decreased risk of subsequent diarrhoea. Lancet 1998; 351: $633-636$.

36 Wren B, Heard SR, Tabaqchali S. Association between production of toxins $\mathrm{A}$ and $\mathrm{B}$ and types of Clostridium difficile. J Clin Pathol 1987; 40: 1397-1401.

37 McFarland LV, Elmer GW, Stamm WE, Mulligan ME. Correlation of immunoblot type, enterotoxin production, and cytotoxin production with clinical manifestations of Clostridium difficile infection in a cohort of hospitalized patients. Infect Immun 1991; 59: 2456-2462.

38 Testore GP, Nardi F, Babudieri S, Giuliano M, Di Rosa R, Panichi G. Isolation of Clostridium difficile from human jejunum: identification of a reservoir for disease? J Clin Pathol 1986; 39: $861-862$.

39 Tsutaoka B, Hansen J, Johnson D, Holodniy M. Antibioticassociated pseudomembranous enteritis due to Clostridium difficile. Clin Infect Dis 1994; 18: 982-984.

40 Vesoulis Z, Williams G, Matthews B. Pseudomembranous enteritis after proctocolectomy: report of a case. Dis Colon Rectum 2000; 43: 551-554. 